\title{
Education and Development: Efforts to Measure Human Well-Being
}

\author{
Adalat Muradovi, Yadulla Hasanli ${ }^{1,2 *}$, Fargana Musayeva ${ }^{3}$ \\ ${ }^{1}$ Azerbaijan State University of Economics (UNEC) \\ ${ }^{2}$ Institute Control Systems of ANAS \\ ${ }^{3}$ Azerbaijan Technical University \\ *yadulla59@mail.ru
}

Article History: Received: 10 November 2020; Revised 12 January 2021; Accepted: 27 January 2021; Published online: 5 April 2021

\begin{abstract}
It is evident from research on economic and social progress that economic growth does not always lead to social progress but, in some cases, leads to increased socio-political tension, social inequality and poverty. Even having increased production of aggregate product on background, the state of the population is deteriorating and economic growth does not provide for a fair distribution of income. A new approach to the concept of economic development began in the global economy in the late XX century. According to these approaches, economic growth cannot be considered as the main purpose and the indicator of development. In addition to economic growth, there are a number of indicators and their mutual relationship promote human development and well-being.

This article examines the correlation between indicators characterizing the welfare of the population and economic growth, comparing the position of Azerbaijan in the accounts of international economic organizations on the relevant indicators. The authors did a comparative analysis with other countries, the impact of human development on people's incomes and the role of education in the wellbeing of the population.
\end{abstract}

\section{Keywords}

Human Development, wellbeing, GDP growth, education, income

\section{Introduction}

In the 1950s, the promotion of industry was declared as a development strategy goal adopted in world countries. The development of industry should have led to an increase in total national wealth, and this, in turn, to an increase in national wealth. But the results showed that without government intervention and without carrying out large-scale social programs, national wealth in and of itself is not able to improve the quality of life and reduce the level of poverty. In spite of the fact that in the 1960s a rapid growth rate was observed in many world countries a notion was formed in those years that economic factors were not an important condition for development. It is no coincidence that in 1962, the UN SecretaryGeneral U.Thant in his speech on the report "The Decade of Development: A Proposal for Action" said: "Development consists not only of economic growth. Development is change along with growth. And change in turn should be like economic and social, and should be both quantitative and qualitative. The main task consists of improving the quality of life".

New approaches to the goals and possibilities of development in economic theory at the end of the twentieth century:

- The economic growth rate cannot be considered as the main goal and indicator of development; 
- There is no direct link between the growth of gross wealth and the prosperous life of people;

- In assessing economic growth, attention should be paid not to the rate of growth, but to quality (its sources and factors);

- Economic growth should not increase the distribution of the population to the strata, and should be aimed at the well-being of future generations, and should also be accompanied by proper guidance (OECD, 1976).

The main position of this new approach, which characterizes the linking of economic and social development, was "ensuring the basic needs of the population". The main postulate of this concept consisted of improving the living conditions of the poor. In those years, unlike traditional views, attention was paid not to economic productivity, but to a reduction in poverty and an improvement in the quality of life. One of the economists who contributed to this concept was the Chilean economist-Manfred Max-Neef who studied the causes of the crises that occurred in Latin America. In the work of an economist provided to the world society in 1986 under the name "Human scale development: conception, application and further reflections", such tasks as social well-being and the provision of basic human needs were investigated. In his opinion, development is about people and not about objects. How can we determine whether one development process is better than another? In the traditional paradigm, we have indicators such as the gross national product... Now we need an indicator about the qualitative growth of people. What should that be? Let us answer the question thus: best development process will be that which allows the greatest improvement in people's quality of life. The next question is: What determines people's quality of life? Quality of life depends on the possibilities people have to adequately satisfy their fundamental human needs. (Max-Neef M., 1991).

Improving well-being is the main goal of every state. Measuring well-being in different countries makes it possible to assess its growth rate, and also makes it possible to determine the provision of the population with minimum standards of living and at what level the economy fulfills its responsibilities (Smith A., 1776). Over the years, economists have considered well-being as a concept that measures individual incomes and includes signs of ensuring the physiological needs of a person. Proponents of this approach paid great attention to the formation and composition of income, as well as the distribution and use of cash income between different groups (Osberg L., 2001).

Later in theories, a multidimensional approach to well-being was applied, taking into account the material and socio-economic (conditions for improving the well-being of individuals, access to education, health care, safety, personal and religious freedom) aspect. That is, wellbeing meant not only income growth, but also the creation of equal opportunities for people, ensuring the socially weak strata of the population with a normal standard of living and a fair distribution of income. By OECD well-being of the population includes 3 main indicators:

- Material living conditions (or economic well-being), which determine people's consumption possibilities and their command over resources.

- Quality of life, which is defined as the set of non-monetary attributes of individuals that shape their opportunities and life chances, and has intrinsic value under different cultures and contexts.

- The sustainability of the socio-economic and natural systems where people live and work, which is important for well-being to last over time (OECD, 2011).

As can be seen, in the OECD approach, quality of life is not used as synonymous with the level of well-being of the population. Quality of life is perceived as an indicator of wellbeing. One of the main indicators used to measure well-being is Human Development İndex. 


\section{Methodology}

In the process of research, the methods of economic-statistical grouping, comparative analysis and the method of least squares were used. The information base consists of the official information of the State Statistics Committee of the Republic of Azerbaijan, the Report of the Human Development Index of the UN Development Program, the Information of the Statistical Institute of UNESCO and the World Bank. The data cover the years 20012017. Models were implemented in the Eviews9 Software Package.

The formation of the first ideas about human development, as well as the methodology of its measurement is associated with the name Mahbub-ul Haq and Amartiya Sen (Haq M.ul., 1995). As noted by Amartiya Sen, the increase in well-being as a result of development should not be measured by the increase in per capita income, but by the opportunity to live the life that they consider themselves worthy. According to the author, the capabilities of a person depend not only on his individual mind and abilities, but also on the social and economic conditions that society provides him. Therefore, the expansion of human choice depends on the conditions, economic, social and political opportunities existing in the country (Sen A., 1987).

The Human Development Index (HDI) developed within the framework of the United Nations Development Program since 1990 and which includes four integral indicators is an indicator that makes it possible to measure the level of well-being along with the level of human development (UNDP, 1990). HDI is considered to be an effective tool for informing the state about existing economic, social and political problems that prevent people from maximizing their opportunities. Because HDI is an indicator that makes it possible to evaluate the results obtained by economic development, health care and education.

Methodology: The novelty of the Human Development Index was that it was a statistical indicator able to characterize both social and economic development. The HDI is the geometric mean of normalized indices for each of the three dimensions:

\section{$H D \dot{I}=\sqrt[3]{\text { I health } * \text { l education } * \text { I income }}$}

Life Expectancy Index - I health - is the most common indicator characterizing public health and the level of medicine. This index is determined on the basis of the number of years that everyone who is born can live.

Education Index - I education - characterizes the development of education and the ability of the population to get an education. This index is measured on the basis of the expected number of school years for each child and the number of years spent on schooling after 25 years.

Gross National Income Index - I income - is calculated by parity of consumer ability and the logarithm of gross national income per capita.

Also, note that the current methodology was introduced in 2010 after changes as a result of long conceptual discussions. The proposed methodological difference was to update the method of adding all three indices in the human development index. The HDI computed in 1990-2009 was based on the mathematical average of subindices $H D \dot{I}=\left(I_{\text {health }}+I_{\text {education }}+\right.$ $I$ income ) / 3. In this method of calculation, sub-indices compensated each other. As, the underestimated level of one indicator was compensated by the overestimated other indicators. As a result, the mathematical indicators characterizing education and health care were weakly expressed in the human development index. But the main feature of the method presented in 2010 was that HDI more clearly reflected the change in each parameter. Another difference was that new indicators were used in the calculation of the Education Index and the Gross National Income Index. Thus, in 1990-2009, the Education Index was calculated on the basis of two other indicators, the literacy rate of the population and the enrollment ratio, and the Gross National Income Index was calculated on the basis of per capita GDP. Literate 
population expressed the number of people 15 years and older who can read, write and perceive. This indicator could not sufficiently clearly reflect the quality of education and functional illiteracy.

HDI varies between 0-1, approaching the unit indicates a high level. $1-0.800$ - shows the ranking of countries with the highest, 0.799-0.700 - with high, 0.699 - 0.550 - with medium, and below 0.550 - with weak human development. This coefficient in Azerbaijan was, equal to 0.640 in 2000, increased to the level of 0.757 in 2017.

As a result, Azerbaijan left the group with an average level of human development and joined the group with a high level of human development. At present, Azerbaijan is in 80th place among 189 countries. In the top three included - Norway (0.953), Switzerland (0.944) and Australia (0.939) (UNDP, 2018).

According to the World Bank, the world's GDP in 2017 was 80.886 trillion dollars (with current prices). Azerbaijan produces GDP in the amount of 40865.6 million dollars, which is $0.05 \%$ of world GDP (World Bank, 2019.). To study the proportionality between the wellbeing of the population and economic development, we calculated the correlation between GDP per capita and human development in 130 countries (Diagram 1.).

As can be seen from the chart, the trend curve has an increasing trajectory. Depending on the interpretation, it can be said that in countries with high GDP per capita, that is, in rich countries, the well-being of the population is also high.

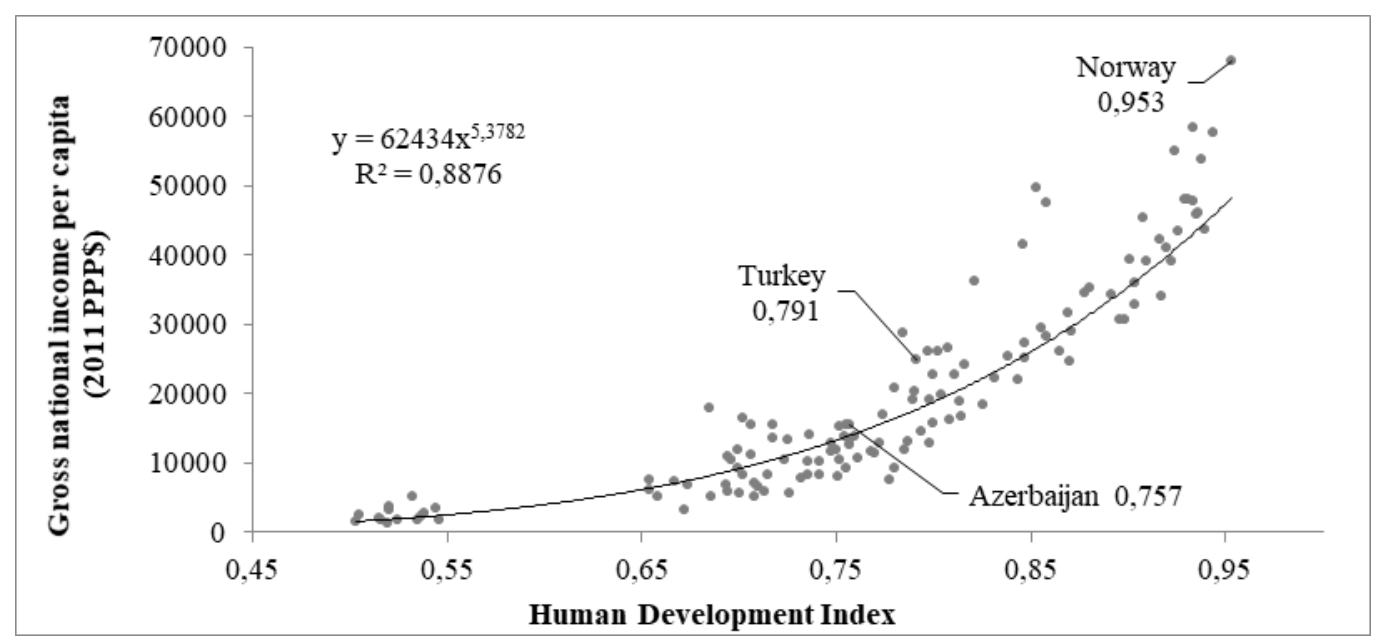

Diagram 1. Gross national income per capita (2011 PPP\$) and Human Development Index (2017)

Source: http://hdr.undp.org/en/data

Studies by international organizations and individual economists prove that investment in human development and education provides for the improvement of material well-being in the long term. At the microeconomic level, the economic benefits of education and its impact on income have been studied in researches of Schultz (1961), Becker (1964), Mincer (1974). The evaluation results carried out using dependencies Mincer show that the private average global return to a year of schooling is $9 \%$ a year. Also note that the estimates were based on 1120 observations conducted in 139 countries during 1950-2014 (Psacharopoulos G., Patrinos H.A. 2018). According to the estimates of the working group on education of the World Bank, an increase in the average duration of education in Azerbaijan was observed with an increase in annual income by 7.2 percent (Montenegro C., Patrinos H.A. 2014).

According to our estimates in Azerbaijan, with a decrease in the level of education, that is, the intellectual level of the head of the family, their income also decreases. The incomes per 
capita of households with the head of families having higher education are greater than those ones who have no schooling by 17.7\%. (Muradov A., Hasanli Y., Musayeva F, 2019).

In assessing the impact of education, more attention was paid to economic growth and income. But new researches are studying the effect of education on human health. A high level of education (especially for women) significantly affects life expectancy and mortality. In 1970-2010 years decline in the mortality rate among people aged 15-60 years in the 1/3, as well as reducing child (under 5 years) mortality rates of $14 \%$ is associated with the education of women. This is explained by the fact that educated women have easier access to health care, on the other hand, they have a greater impact on their lives and the lives of their children, and on managing the economy. According to the results of research in the studied years one dollar invested in an additional year of schooling, particularly for girls, generates earnings and health benefits of \$10 in low-income countries and nearly \$4 in lower-middleincome countries (Schäferhoff M., Dean J., 2016).

Studies show that there is a positive relationship between parental education and that of their children. According to the results of research children who have both parents with low education (secondary, primary), at best have a chance to get a university education in $15 \%$. In families of which at least one of the parents received a university education, this chance for children reaches $60 \%$ (OECD, 2018).

\section{Findings}

To study the proportionality between material well-being and the level of education of the population, we calculated correlations between the average annual, average monthly salary and the education index in 60 countries of the world (Diagram 2.). There is a scattering of developed western countries close to the trend curve. This indicates that in these countries there is a dependence between the level of education and incomes of the population. As can be seen from the diagram, at the bottom of the trend curve there is a group of countries that is scattered with large deviations. These are the poor states of Africa and the East as Surya, Bangladesh and Afghanistan. This is due to the political and economic situation, the shortage and inefficient use of human capital. Sometimes it is impossible to achieve income growth by increasing the level of education and improving the coverage ratio of education. The overall political situation, the level of fees and investments, income distribution are considered important determinants in countries. If there is no demand for labor in the labor market, in other words, people have a low employment opportunity, then the increase in the number of educated people in this country increases the number of literate unemployed. On the other hand, if in the labor market wages are not proportional to the complexity and quality of labor, then education loses its social significance.
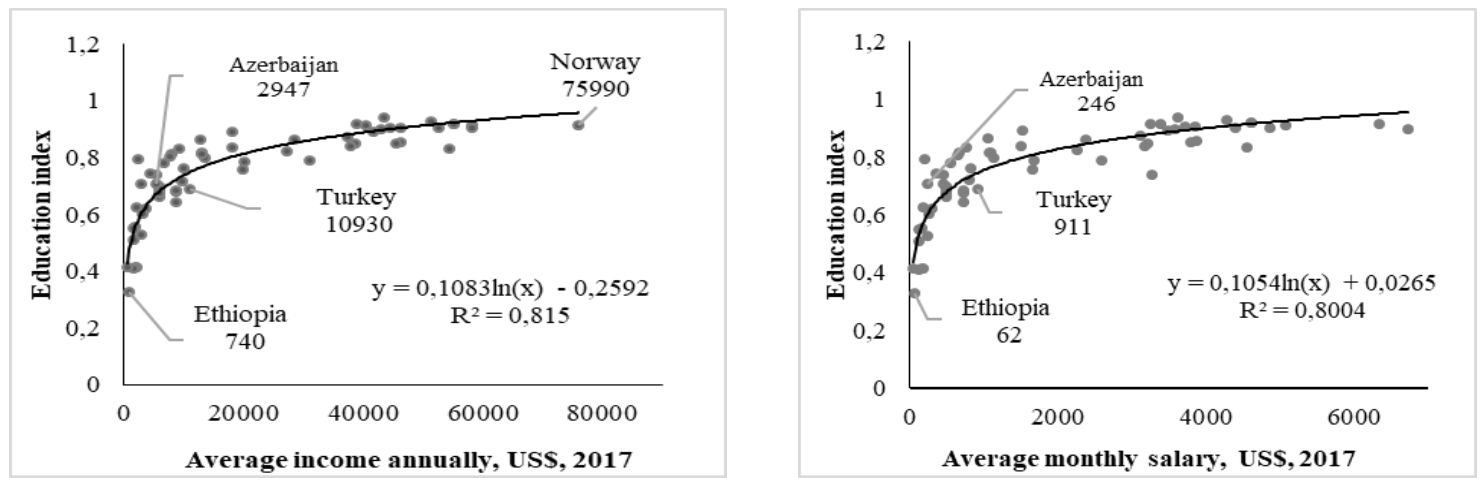

Diagram 2. Education index, average income annually and monthly salary (2017) Source: https://www.worlddata.info/average-income.php, http://hdr.undp.org/en/content/educationindex 
Note that in Azerbaijan, in fact, regardless of the geographical location and incomes of the population, children complete a nine-year education (general secondary schools). Therefore, the overall literacy rate in the country is 99.8 percent. Despite the fact that children have positive trends in participation in education, opportunities for higher education are limited. Coverage rate of primary and general secondary education is $100 \%$, and higher education is $33 \%$. The result of this is that in 2017 the number of people with higher education among the population of 15 years and above is only $13.3 \%$. To assess the material well-being of the population, we will use sample surveys of household budgets prepared by the statistical observation method by the State Statistics Committee of the Republic of Azerbaijan. The amount of monthly income per person in a family increased 4.9 times compared with 2001 and reached 157.9 US dollars (Table 1). And the amount of monthly expenses per person in a family grew 4.6 times and reached 163.7 US dollars. As can be seen from the table, with the growth of incomes of the population, the volume of expenditures on education also increased. This indicator in 2001 was equal to 0.44 dollars, and in 2017, to 3 dollars. During the 16 years reviewed, expenditure on education increased 6.9 times.

Table 1. Income and expenditures of households (current prices, US\$2017)

\begin{tabular}{lcccc}
\hline Years & $\begin{array}{c}\text { İncome of households } \\
\text { (per capita, per month) }\end{array}$ & $\begin{array}{c}\text { Consumption expenditures } \\
\text { of households } \\
\text { (per capita, per month) }\end{array}$ & Difference & $\begin{array}{c}\text { Education expenditures } \\
\text { of households } \\
\text { (per capita, per month) }\end{array}$ \\
\hline 2001 & 32.3 & 35.3 & -3 & 0.44 \\
2010 & 180.3 & 184.3 & -4 & 2.8 \\
2017 & 157.9 & 163.7 & -5.8 & 3 \\
\hline
\end{tabular}

Source: https://www.azstat.org/portal/tblInfo/TblInfoList.do\#994_025

The following results were obtained from the econometric estimation of dependence between family income and education expenditure.

DLOG $($ EXPENDIT $)=0.041686+0.806659 *$ DLOG $($ INCOME $)$

(1)
(s.e.)
$(0.044567)$
$(0.202289)$

R-squared $=0.531794 \quad$ Adjusted R-squared $=0.498351 \quad$ Durbin-Watson stat $=1.976627$

here,

DLOG (EXPENDIT) - expenses for family education during the month,

DLOG (INCOME) - income for families during the month,

S.E. - standard error parameters,

R-squared - determining coefficient,

Adjusted R-squared - shows the specified determinant coefficient,

Durbin-Watson stat - is a test for autocorrelation in a data set.

In Eviews the main statistical characteristics and other relevant tests shown in the table taken from the regression equation and other relevant tests show that the model is adequate. The statistical studies and correlations indicate that families are interested in investing in education. Thus, the growth of monthly income per person in families by $1 \%$, contributed to the growth of expenditures on education by $0.81 \%$.

At the next stage, we will assess the impact of education expenditures on household income at the macroeconomic level. Note that education expenses by country can be classified in 3 groups:

- $\quad$ Expenditures from the state budget

- Family Education Expenditures

- Funds for staff development allocated by institutions. 
Due to the fact that there is no data on the last item SSCAR, we will introduce two items of expenditure into our research. The calculations show that in the country, expenditures on education increased by 5.6 times compared with 2001 and reached 1,368.9 million dollars in 2017. Approximately $1 / 4$ of the cost of education falls to the share of families. Family spending on education in 2017 amounted to 356.3 million dollars, and in 200143.7 million dollars.

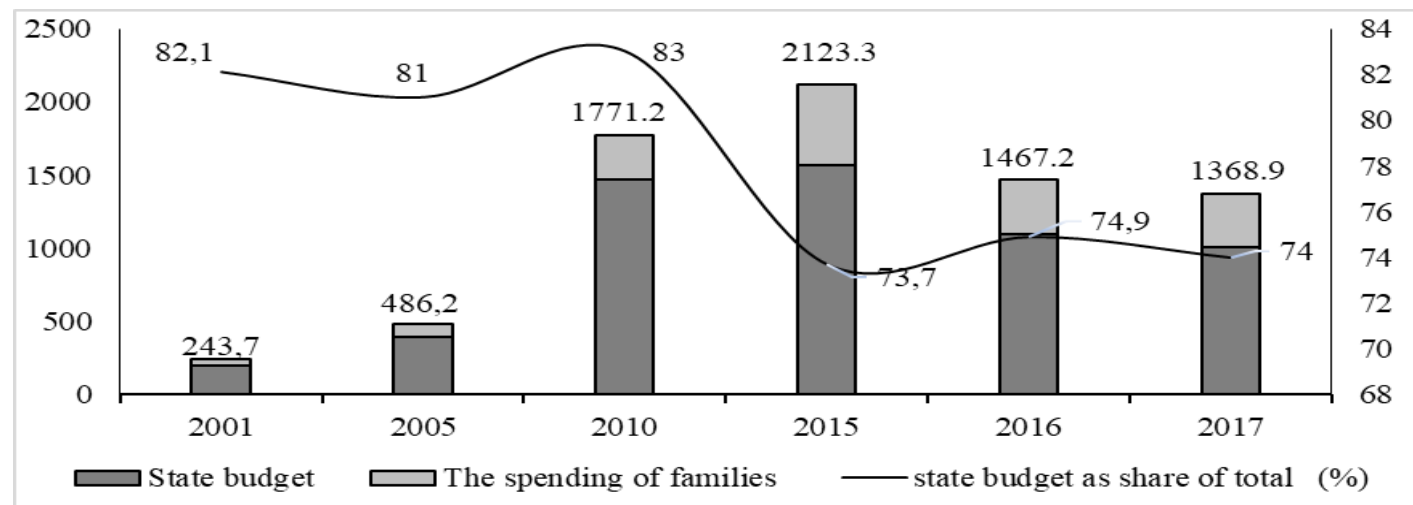

Diagram 3. Education expenses (million, US\$)

Source: https://www.azstat.org/portal/tblInfo/TblInfoList.do\#994_025 and https://www.azstat.org/portal/tblInfo/TblInfoList.do\#994_020

And the budget expenditures on education in 2017 amounted to 1012.6 million dollars. As can be seen from the diagram, the amount of funds allocated from the budget has been growing since 2001. Due to the devaluation in 2015, there is a relative decline in spending in dollar terms. Although spending on education has increased since 2001, this is lower compared with the growth in general government spending. Compared to 2001, general government expenditures increased 11.8 times, and expenditures on education 5.1 times. As a result, the share of expenditure on education in total expenditures decreased from $23.1 \%$ to $9.9 \%$. In 2017, the amount of funds allocated from the state budget for education was $2.5 \%$ of GDP. Note that according to the World Bank, this figure in the world is $4.8 \%$, in countries with high incomes of $5.2 \%$, in countries with low incomes $3.5 \%$, in heavily indebted poor countries $4 \%$.

The result of the regression equation that measures the impact of education expenditure on population income is as follows:

$$
\begin{aligned}
& \text { LOG }(\text { INCOME_ANNUAL })=3.48262474601+0.955882235974 * L O G\left(E X P \_E D U\right) \\
& \text { (s.e.) (1.183194) (0.202289) }
\end{aligned}
$$

R-squared $=0.893654 \quad$ Adjusted R-squared $=0.886564 \quad$ Durbin-Watson stat $=1.784233$

here,

LOG(EXP_EDU) - the total education expenditure in the country

LOG(INCOME_ANNUAL) - population's income

In Eviews the main statistical characteristics and other relevant tests shown in the table taken from the regression equation and other relevant tests show that the model is adequate. As it is seen from the equation, the $1 \%$ increase in the education expenditures was reflected in the increase in the income of the population by $0.96 \%$.

\section{References}

[1] Becker, G. (1964) Human Capital. Chicago: University of Chicago Press

[2] Haq, M. ul. (1995) Reflections on Human Development, Oxford University Press, Oxford

[3] Max-Neef, M. (1991). Human Scale Development: conception, application and further 
reflections. New York : The Apex Press, 114 p.

[4] Mincer, J. (1974) Schooling, Experience and Earnings, National Bureau of Economic Research, Cambridge, MA.

[5] Montenegro C., Patrinos H. (2014) Comparable Estimates of Returns to Schooling around the World. World Bank Policy Research Working Paper Series 7020.

[6] Muradov A., Hasanli Y., Musayeva F (2019) Estimation of the Education Influence on the Population Income. 37th Int. Scie. Conf. on Econ. and Social Development - "Socio Economic Problems of Sustainable Development". 4-15 February, 2019. pp. 592-602.

[7] OECD (1976), Measuring Social Well-being: A Progress Report on the Development of Social Indicators, Paris

[8] OECD (2011) Compendium of OECD Well-Being Indicators. OECD, Paris, 37 pp.

[9] OECD (2018) A Broken Social Elevator? How to Promote Social Mobility.

[10] Osberg, L. (2001), "Comparisons of Trends in GDP and Economic Well-being - The Impact of Social Capital", in J.F. Helliwell (ed.), The Contribution of Human and Social Capital to Sustained Economic Growth and Well-being: International Symposium Report, Human Resources Development Canada and OECD.

[11] Psacharopoulos G., Patrinos H. (2018) Returns to investment in education: a decennial review of the global literature. EDUCATION ECONOMICS 2018, VOL. 26, NO. 5, 445-458

[12] Schultz, Theodore W. 1961. "Investment in Human Capital." American Economic Review 51(1): pp. 1-17.

[13] Schäferhoff M., Dean J. (2016) "Estimating the Economic Returns of Education from a Health Perspective." Background Paper for the Education Commission. SEEK Development (SEEK).

[14] Sen, A. (1987) The Standard of Living, Cambridge University Press, Cambridge.

[15] Smith, A. (1776), The Wealth of Nations, Book I.

[16] The State Statistical Committee of the Republic of Azerbaijan (2018), Statistical İnformation service, https://www.stat.gov.az/. Accessed 6 April 2019.

[17] UNDP (1990) Human Development Report 1990: Concept and Measurement of Human Development. Oxford University press.

[18] UNDP (2018) Human Development Indicators and Indices: 2018 Statistical Update Team, New York, $112 \mathrm{p}$.

[19] World Bank (2019) World Development Indicators data-base. Washington, DC. http://data.worldbank.org. Accessed 6 April 2019. 